Boise State University

ScholarWorks

Educational Technology Faculty Publications and Presentations

11-18-2019

\title{
Understanding Second Grader's Computational Thinking Skills in Robotics Through Their Individual Traits
}

\author{
Youngkyun Baek \\ Boise State University, youngkyunbaek@boisestate.edu \\ Dazhi Yang \\ Boise State University, dazhiyang@boisestate.edu \\ Yibo Fan \\ Boise State University
}

Follow this and additional works at: https://scholarworks.boisestate.edu/edtech_facpubs

Part of the Educational Assessment, Evaluation, and Research Commons, Educational Psychology Commons, Elementary Education Commons, Instructional Media Design Commons, and the Science and Mathematics Education Commons

Publication Information

Baek, Youngkyun; Yang, Dazhi; and Fan, Yibo. (2019). "Understanding Second Grader's Computational Thinking Skills in Robotics Through Their Individual Traits". Information Discovery and Delivery, 47(4), 218-228. https://dx.doi.org/10.1108/IDD-09-2019-0065 


\title{
Understanding Second Grader's Computational Thinking Skills in Robotics Through Their Individual Traits
}

\author{
Youngkyun Baek* \\ Department of Educational Technology \\ Boise State University \\ youngkyunbaek@boisestate.edu
}

\author{
Dazhi Yang \\ Boise State University
}

\author{
Yibo Fan \\ Boise State University
}

\begin{abstract}
This study investigated the relationship between the personal traits and computational thinking skills of second graders within the context of robotics activities. The hypothesized model showed that learning preference, intrinsic motivation, and self-efficacy were the main predictors of coding achievement and computational thinking skills, while no direct relationship was found between learning preference, intrinsic, or extrinsic motivation. The final path analysis revealed that intrinsic and extrinsic motivation predict self-efficacy, self-efficacy predicts coding achievement, and coding achievement predicts computational thinking skills. Another important finding was the strong impact of self-efficacy on coding achievement as well as computational thinking skills. Results are interpreted with reference to implications for potential methods of improving computational thinking skills when using robotics in the lower grades in elementary schools.
\end{abstract}

Keywords: robotics, intrinsic motivation, extrinsic motivation, self-efficacy, coding achievement, computational thinking skills

\section{Introduction}

Robotics, as a promising new way to engage students in STEM (Atmatzidou \& Demetriadis, 2016), can benefit students in various ways such as inspiring them to engage in STEM careers (Gomoll, Hmelo-Silver, Šabanović, \& Francisco, 2016; Master, Cheryan, Moscatelli, \& Meltzoff, 2017), enhancing students' higher order thinking skills (Blanchard, Freiman, \& Lirrete-Pitre, 2010), and improving students' science literacy (Sullivan, 2008). The integration of robotics into education has gained increasing attention from researchers and teachers alike, and is being widely introduced in schools from kindergarten to university (Xia \& Zhong, 2018). In particular, robotics in elementary schools has attracted significant interest over the past few years, and numerous empirical studies on the effects of robotics on young students have been conducted. For instance, Hong, Yu, and Chen (2011) reported that elementary students' collaboration and problem-solving skills were enhanced by engaging in robot design activities. Students reflected deeply on the design challenges they engaged in, in addition to cooperating with peers (Hong et al, 2011). Barker and Ansorge (2007) implemented an after-school program where science and technology courses integrated robotics for 9-11 years old students. Their findings indicated that robotics was an effective tool for teaching students science, engineering, and technical concepts. The application of robotics in schools is not, however, confined to only science-related subjects; it has great potential in other subjects as well. For example, Chang and colleagues (2010) used a humanoid robot to teach a second language in an elementary school. Results suggested that the students were more motivated to learn in the interactive and engaging learning environment created by the robot (Chang et al., 2010).

In her seminal paper on computational thinking (CT), Wing (2006) proposed that CT "represents a universally applicable attitude and skill set for everyone, not just for computer scientists, who would be eager to learn and use" (p. 33). Since then, the studies on CT around the world have been accumulating momentum, covering a wide range of topics such as the integration of CT in K-12 education (Sengupta, Kinnebrew, Basu, Biswas, \& Clark, 2013; Yadav, Hong, \& Stephenson, 2016), the development of CT (Ching, Hsu, \& Baldwin, 2018; Ioannou \& Makridou, 2018), and the assessment of CT (Chen et al., 2017; Zhong, Wang, Chen, \& Li, 2016). Despite the myriad of ways to foster CT, 
This is an author-produced, peer-reviewed version of this article. The final, definitive version of this document can be found online at Information Discovery and Delivery, published by Emerald Group Publishing, Ltd. Copyright restrictions may apply. doi: 10.1108/IDD-092019-0065

the development of CT through robotics has attracted the most attention. For instance, Leonard et al. (2016) described a pilot study in which LEGO EV3 robotics and game design were used to develop middle school students' CT strategies. Their findings indicated that students' CT strategies were improved as a result of engaging in robotics and game design. Atmatzidou and Demetriadis (2016) showed that junior high and high school vocational students' CT skills were improved significantly towards the end of the learning activity with Lego Mindstorms NXT.

Broadly speaking, existing studies on the application of robotics in education show that educational robots can foster students' cognitive and social skills (Ioannou \& Makridou, 2018), with some studies indicating that the use of robotics can improve students' CT skills (Atmatzidou \& Demetriadis, 2016; Leonard et al., 2016). However, there is a paucity of studies investigating the personal traits (e.g., self-efficacy) relating to the development of CT skills in the context of educational robotics at the elementary school level. Moreover, in their review of the potential of using robotics to develop CT skills, although Ioannou and Makridou (2018) identified 9 empirical studies published as of 2016, notably, none of those studies were conducted in the context of elementary education. To fill this gap in research, students' personal traits (e.g., self-efficacy, learning preference, and motivation, etc.) in relation to CT skills in robotics were explored in this study. The research question that guided this study was: What are the personal traits that influence coding achievement and computational thinking skills of second grade students in robotic activities?

\section{Literature Review for Constructing Hypotheses}

In this section, the authors reviewed previous relevant studies on the six variables of interest in this study, namely, learning preference, intrinsic motivation, extrinsic motivation, self-efficacy, coding achievement, and computational thinking skills. Based on the review, the rationale for the seven proposed hypotheses was presented. Moreover, a research model that contained the relationships between variables was developed.

\subsection{Learning Preference, Motivation and Self-Efficacy}

Self-efficacy, as defined by Bandura (1986), is "people's judgments of their capabilities to organize and execute courses of action required to attain designated types of performances” (p. 391). Over the years, self-efficacy has been studied in various academic subject areas, and a range of specific measures have been produced (Aesaert \& Van Braak, 2014). For example, mathematical self-efficacy (Ozgen, 2013), ICT self-efficacy (Aesaert \& Van Braak, 2014), reading self-efficacy (Baker \& Wigfield, 2011), and computer self-efficacy (Shiue, 2005).

However, to the best knowledge of authors in this study, no studies have investigated the relationship between learning preference and self-efficacy in K-12 robotics learning environment. To fill this gap, this exploratory study thus hypothesized that students' learning preference is positively related to self-efficacy:

\section{H1: Student's learning preference is positively related to self-efficacy.}

As proposed by Oxford and Shearin (1994), motivation is regarded as "a built-in unconscious striving towards more complex and differentiated development of the individual's mental structures” (p. 23). And since motivation is a very broad concept, it is hard to cover all its aspects (de Brabander \& Martens, 2014). For instance, self-determination theory only distinguished between two kinds of motivation: intrinsic and extrinsic motivation (Deci \& Ryan, 1985; Jon Chao Hong, Hwang, Tai, \& Lin, 2017). Further, intrinsic motivation refers to "doing an activity for the inherent satisfaction of the activity itself" (Ryan \& Deci, 2000, p. 71). Prior studies have demonstrated that when learners are faced with challenges, those who are intrinsically motivated tend to persist more than those who are extrinsically motivated (Grant, 2008). As described above, self-efficacy has been studied in various subject areas, and is perceived as an important facet when investigating human learning.

Quite a few of the studies have been conducted to investigate the relationship between intrinsic motivation and selfefficacy. Hong et al. (2017) found that the intrinsic motivation of learning Chinese could predict online learning selfefficacy. Similar results could be found in another study in which the intrinsic motivation, combined with extrinsic motivation and academic achievement, could predict students' social studies self-efficacy and is accountable for $64 \%$ of self-efficacy variance (Kılıçoğlu, 2018). Based on the above listed evidence, this study hypothesized that students' intrinsic motivation is positively related to self-efficacy:

H2: Student's intrinsic motivation is positively related to self-efficacy. 
This is an author-produced, peer-reviewed version of this article. The final, definitive version of this document can be found online at Information Discovery and Delivery, published by Emerald Group Publishing, Ltd. Copyright restrictions may apply. doi: 10.1108/IDD-092019-0065

Extrinsic motivation refers to the performance of activities driven by an outcome or by external factors (e.g., personal benefits such as promotion) (Ryan \& Deci, 2000). Self-efficacy is perceived by an individual as successfully performing a given task (Huang \& Liaw, 2007), and as proposed by Bandura (1977), self-efficacy can be connected to certain behaviors related to achievement, for example, skills performance, motivation, and choice of activities. Studies have been conducted to investigate the relationship between extrinsic motivation and self-efficacy (e.g., Kılıçoğlu, 2018; Liao, Edlin, \& Ferdenzi, 2014; McGeown et al., 2014). For instance, Kılıçoğlu (2018) found that extrinsic motivation combined with intrinsic motivation and academic achievement could explain $64 \%$ of the variance in self-efficacy. Liao et al. (2014) found that self-efficacy measures had a strong correlation with both intrinsic and extrinsic motivation measures. McGeown et al. (2014) revealed that self-efficacy predicted significant variances in extrinsic motivation. The studies reviewed above confirmed an existing relationship between self-efficacy and extrinsic motivation regardless of which one is the predictive variable in research. Thus, this study hypothesized that students' extrinsic motivation is positively related to self-efficacy:

H3: Student's extrinsic motivation is positively related to self-efficacy.

As reviewed above, various studies have investigated the relationship between extrinsic motivation and self-efficacy (e.g., Kılıçoğlu, 2018; Liao et al., 2014; McGeown et al., 2014). And it was hypothesized in H3 that students' extrinsic motivation is positively related to self-efficacy. Numerous studies indicated that self-efficacy has a positive relationship with academic performance (e.g., Richardson, Bond, \& Abraham, 2012; Robbins, Lauver, Le, David, \& Langley, 2004). And H5 in this study hypothesized that students' self-efficacy is positively related to coding achievement. Moreover, given the paucity of studies directly investigating the relationship between extrinsic motivation and coding achievement, an indirect hypothesis that student's extrinsic motivation is positively related to coding was proposed based on $\mathrm{H} 3$ and $\mathrm{H} 5$.

H4: Student's extrinsic motivation is positively related to coding achievement.

H5: Student's self-efficacy is positively related to coding achievement.

\subsection{Self-Efficacy, Coding, and Computational Thinking Skills}

Self-efficacy is one of the most prominent factors that drive and regulate people's behaviors, which refers to an individual's "judgments of their capabilities to organize and execute courses of action required to attain designated types of performances" (Bandura, 1986, p. 391). Within the academic context, self-efficacy is usually described in the term of academic self-efficacy (ASE) (Honicke \& Broadbent, 2016), which, according to Elias and MacDonald (2007), refers to learners' judgement of one's ability to successfully achieve educational goals. Numerous studies have been conducted to highlight the importance of ASE for academic performance across a wide range of learning environments from elementary education (Joët, Usher, \& Bressoux, 2011) to high school (Alivernini \& Lucidi, 2011) and university (Robbins et al., 2004). Notably, regardless of the different learning environments, ASE has shown a consistent positive correlation with academic performance, reporting a moderate effect size (Richardson et al., 2012; Robbins et al., 2004). In this study, the coding achievements of participating second graders were evaluated in two ways, namely, the designed robots and coding at code.org. The students were required to design a robot which could successfully locate "water" in a simulated Mars environment and complete 12 coding items at code.org. Computational thinking skills were tested using the computational thinking test developed by Roman-Gonzalez (2015). Both coding achievements and computational thinking skills can be included under the realm of academic performance.

Few studies have been conducted to investigate self-efficacy in the context of robotics (coding and computational thinking more specifically). However, given the consistent positive correlation between self-efficacy and academic performance as evidenced in previous research (e.g., Richardson et al., 2012; Robbins et al., 2004), this study proposes the following two hypotheses, namely, H5: Student's self-efficacy is positively related to coding achievement, and H6: Student's self-efficacy is positively related to computational thinking skills.

H6: Student's self-efficacy is positively related to computational thinking skills.

H7: Student's coding achievement is positively related to computational thinking skills. 
During the coding activities in this study, students had ample opportunities to practice a wide range of skills. For instance, students needed to work in groups and communicate with each group member to code their robots in such a way that the robots could successfully locate "water" in a Mars simulation. Throughout the process, students not only practiced their communication skills, they also improved their conditional logic, data collection, data analysis, and decomposition skills. Yang et al. (2019) reviewed previous studies on computational thinking in elementary schools and summarized various components reflected in different computational thinking definitions, including communication, data collection, data analysis, and conditional logic. Since these components are inherently practiced in the coding activities in this study, it was hypothesized that students' coding achievement is positively related to computational thinking skills:

H7: Student's coding achievement is positively related to computational thinking skills.

\section{Materials and Methods}

\subsection{Research Model and Hypotheses}

Based on the aforementioned hypothesized relationships, the research model was constructed to illustrate the assumed interrelationships of the variables studied. The purpose of this study was twofold: a) to investigate whether individual traits- e.g., learning preference, intrinsic motivation, self-efficacy and coding achievement- could predict the levels of computational thinking skills, and b) to explore the relationship between self-efficacy and coding achievement, and computational thinking skills.

The hypothesized model was constructed based on seven hypotheses. First, this study sought to explore learning preference as a predictor of self-efficacy. Since learning preference represents differences in how students prefer to learn, the study assumed that participants with certain learning preference would affect self-efficacy. Intrinsic and extrinsic motivation also could be predictors of self-efficacy. Additionally, extrinsic motivation and self-efficacy were assumed to be predictors of coding achievement. Lastly, coding achievement and self-efficacy were introduced as predictors of computational thinking in an attempt to explore whether there was a direct association between coding achievement and computational thinking skills, and between self-efficacy and computational thinking skills.

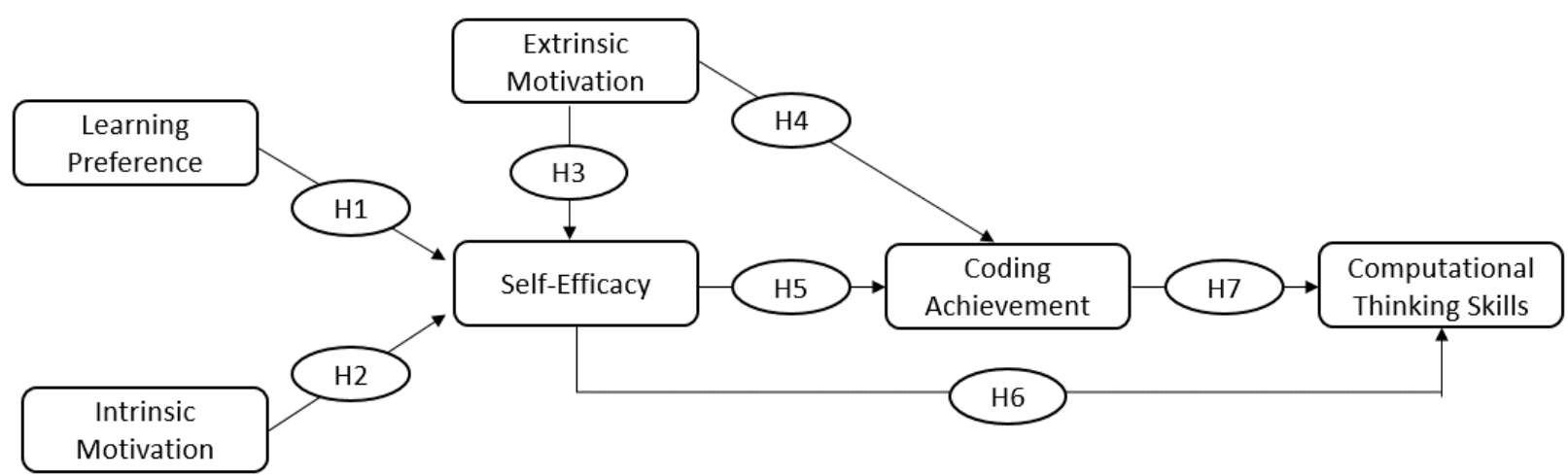

Figure 1. The hypothesized model

H1: Student's learning preference is positively related to self-efficacy.

H2: Student's intrinsic motivation is positively related to self-efficacy.

H3: Student's extrinsic motivation is positively related to self-efficacy.

H4: Student's extrinsic motivation is positively related to coding achievement. 
This is an author-produced, peer-reviewed version of this article. The final, definitive version of this document can be found online at Information Discovery and Delivery, published by Emerald Group Publishing, Ltd. Copyright restrictions may apply. doi: 10.1108/IDD-092019-0065

H5: Student's self-efficacy is positively related to coding achievement.

H6: Student's self-efficacy is positively related to computational thinking skills.

H7: Student's coding achievement is positively related to computational thinking skills.

\subsection{Participants}

The participants in this study were 122 second graders from five classes in an elementary school in Boise, Idaho. All of the students were excited about the prospect of learning about Mars, robots, building, and programming their own robots, though most had no prior robotics experience. Most students had limited resources or exposure to coding, except for what they had done once or twice at school through code.org. There were 55 male and 67 female students participating in this study with their age ranging from seven to eight years old.

\subsection{Procedure and Data Collection}

Before the intervention began, teachers from five classes discussed a pre-prepared lesson plan that was made by the researchers and one teacher. The researchers explained the intervention in detail, as well as about the questionnaires they would administer before and after the intervention. Teachers fully understood the lesson plan and shared the objectives and procedures of the intervention.

The robotics activities lasted for 13 days for 45 minutes per day. During the robot design portion of the lesson, the instructors made a circle map about robotics led by a question: What do you know about robotics? Before the programming part of the lesson, students talked about what they knew about coding, relating back to code.org which they had already done throughout the program. A teacher demonstrated giving and receiving instructions, and then executing them, showcasing the importance of simple and precise directions. Then students practiced by playing the role of the robot, similarly receiving and executing simple commands. This was an engaging and helpful way to build an understanding of the specifics of coding, as code has to be exact since robots cannot figure out what to do on their own.

Same-gender groups were created which allowed the girls to be more engaged and interactive with what is typically considered "boy toys". The younger girls in the second grade needed the support of older 6th grade girls to get them started with the LEGO robot designs, whereas the boys immediately jumped into their designs without hesitation. Once students started the robot building, they were shown how the blocks click together and how to build wheels. The girls were able to quickly complete the building of the robots as quickly as the boys did in the program. On the LEGO robots redesign day, the girls and boys were equally independent.

Question type and questioning techniques, are the most crucial part of pushing understanding with students. For example, initially getting the students to determine "why would we send a robot to Mars instead of an astronaut" helped them focus on the type of information we were looking for, and also built interest in the activity. When students were in the process of designing and building their own robots, questions like "what is it you want your robot to do?" and "how will it do that?" helped keep the students focused on the facts they had learned about Mars, why we would send a robot there and what the intention of the design was. Teachers utilized students' prior knowledge about how their own bodies work to connect the robot parts. For example, actuators/motors can move in reaction to feedback from its sensors. This leads into the idea of the robot 'brain' as a control system that does not work on its own.

In order to accomplish a given task, a robot needs to receive a series of commands since they operate off of 'instructions'. Students studied basic commands and practiced writing algorithms, coding, and debugging. Students performed hands-on coding activities that taught them code-specific symbols, how robots would potentially react to symbols, and how detailed and specific coding needs to be. For example, students worked in groups of three and each student had a specific role (robot, code writer, and speaker). The robot only did what the speaker said after the code writer wrote the appropriate symbol. The speaker used code-specific terminology for the code writer and robot to follow. The code writer only wrote what the speaker said. An extension for this activity additionally included the concept of loops. Throughout this activity, a computational problem-solving process was used to guide student thinking and problem-solving when the students in the role of the robot did not do what the speaker and/or code writer said. 
This is an author-produced, peer-reviewed version of this article. The final, definitive version of this document can be found online at Information Discovery and Delivery, published by Emerald Group Publishing, Ltd. Copyright restrictions may apply. doi: 10.1108/IDD-092019-0065

After two days of coding lessons, teachers provided information about Mars to develop students' background knowledge about a problem that they would solve with their robots later in the unit. Students also spent some time on PebbleGo researching Mars and outer space more in detail. Language support was provided through the explicit teaching of vocabulary words and using Thinking Maps to organize thinking and research.

Students rotated between 3-4 stations that supported different parts of the problem-solving process and coding. Two stations were teacher guided; these stations were identical and allowed students to build the Lego WeDo 2.0 Robots following directions in its app. Students took turns building one step at a time until the robot completed. Students rotated between another station using code.org to continue having additional opportunities to practice coding. The last station allowed students to create their own robot models using Legos. Students were expected to draw a detailed design and build the same model. Students then redesigned their model by predicting what obstacles their model may experience as if it were on Mars. Teachers created a problem for students to solve using their knowledge of coding and of the computational problem-solving model. Students worked independently and in small groups.

Closure activities followed the computational thinking map (wheel). Students reviewed the map for how it was used it, how their computational thinking was used to guide their coding, designing, redesigning, etc. They associated ideas from how computational thinking was used to past lessons and even lessons like math, unrelated to the STEM project.

\subsection{Psychometric Properties of Measures}

\subsubsection{Learning preference}

The learning preference in this study was measured using the "Problem Solving Style Questionnaire" developed by Duff (2004). This scale consisted of two constructs: concreteness versus abstractness and reflection versus action. The first construct has seven items. One item has a six-point Likert scale gauging concreteness to abstractness. The higher the score becomes, it moves from concreteness to abstractness. The second construct, reflection versus action, has the same seven items. If the score gets higher, it moves from reflection to action. The scale with two constructs is positively and strongly correlated with academic achievement showing that the most effective learners are likely to emphasize abstract conceptualization and active experimentation. Thus, he concludes that the scale of fourteen items is valid and useful as a measure of learning preference.

\subsubsection{Intrinsic and Extrinsic Motivation}

The Intrinsic Motivation Inventory (IMI) can be used to assess users' subjective experience with computer games and was used in previous studies related to intrinsic motivation (Ryan,1982; Ryan, Mims, \& Koestner, 1983; Ryan, Koestner, \& Deci, 1991). The IMI instrument contains 45 items and assesses users' experiences on seven dimensions: interest/enjoyment, perceived/competence, effort/importance, pressure/tension, perceived choice, value/usefulness, and relatedness. McAuley, Duncan, and Tammen (1987) conducted a study to test the validity of IMI and concluded that as many or as few of the items of the items can be used without having a significant impact on the psychometric aspects of the instrument. Hanus and Fox (2015) also reported a Cronbach alpha value of 0.86 on the 22-item scale used by Ryan et al. (1991). As such, the scale used in this study comprises 25 items within four subscales: interest/enjoyment, perceived choice, perceived competence, and pressure/tension. Items in IMI are measured on a 7point Likert scale from 1 (strongly disagree) to 7 (strongly agree).

\subsubsection{Self-Efficacy}

Self-efficacy was measured using the perceived competence subscale of the Intrinsic Motivation Inventory (IMI) which was used in previous studies related to intrinsic motivation (Ryan, 1982; Ryan et al., 1983; Ryan et al., 1991). This measure includes 6 items, such as "I think I am pretty good at this activity," and one negative item, "This was an activity that I couldn't do very well.” Each item was assessed using a 7-point Likert scale from 1 (strongly disagree) to 7 (strongly agree). The scale has been shown to be reliable and valid (McAuley et al.,1989). Cronbach's alpha for the subscale was strong, $\alpha=.80$. 
This is an author-produced, peer-reviewed version of this article. The final, definitive version of this document can be found online at Information Discovery and Delivery, published by Emerald Group Publishing, Ltd. Copyright restrictions may apply. doi: 10.1108/IDD-092019-0065

\subsubsection{Coding Achievement Test}

Coding achievement of students was evaluated using two methods: The first test was the evaluation of students' coding project and the other was a test on code.org. The final project was to individually code a robot to reach a fountain on Mars (see Figure 2). Students' final projects were evaluated using a rubric (see Table 1) by two researchers and the mean score was adopted as one of the coding achievement scores.

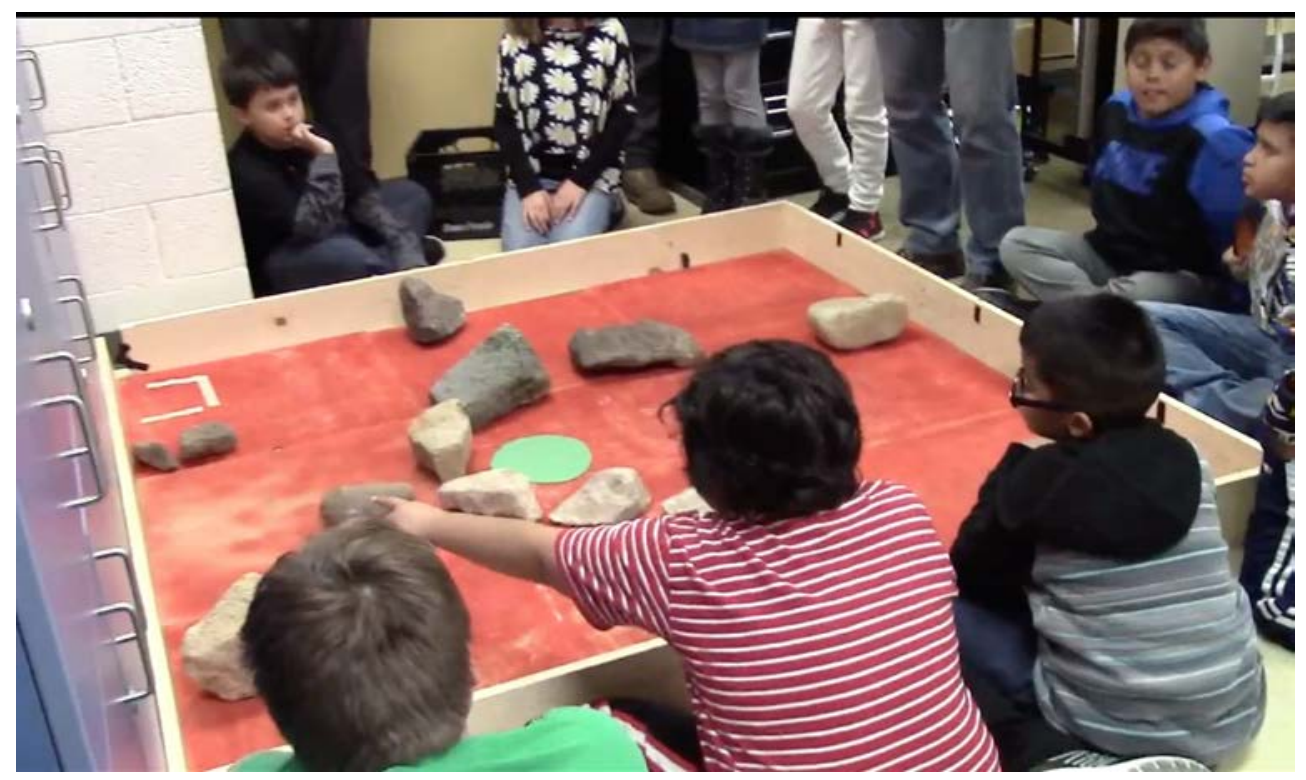

Figure 2. Mars simulator for students' robot and coding project.

Table 1

Rubric for the coding and robot activity (searching water on Mars)

\begin{tabular}{|l|c|c|c|c|c|}
\hline Criteria/Score & $0-2$ & $3-4$ & $5-7$ & $6-8$ & $9-10$ \\
\hline Completion & $<70$ & $70-79$ & $80-89$ & $90-99$ & 100 \\
\hline Trial Number & $>$ Fourth & Fourth & Thrice & Twice & Once \\
\hline $\begin{array}{l}\text { Time (minutes) to } \\
\text { Water }\end{array}$ & $>7$ & $6-7$ & $5-6$ & $3-4$ & $1-2$ \\
\hline Number of Collisions & $>6$ & $5-6$ & $3-4$ & $1-2$ & 0 \\
\hline
\end{tabular}

The second test consisted of twelve items for second graders. The test-retest reliability for the second test was .89. The sum of the two scores was used as students' coding achievement.

\subsubsection{Computational Thinking Skills}

The Computational Thinking Test created by Roman-Gonzalez (2015) was used to assess participants' computational thinking skills. This is a 28-item test which consists of multiple-choice questions with four answer options, only one of which is correct. Answer options are either visual arrows or visual blocks. Questions require students to complete one of three cognitive tasks: sequencing commands, completion of incomplete commands, or debugging incorrect commands. Test completion requires about 45 minutes. Internal consistency reliability was found to be good (Cronbach's alpha; 0.793). Roman-Gonzalez, Perez-Gonzalez, and Jimenez-Fernandez (2016) concluded there is powerful evidence of the criterion concurrent validity of the test. 


\section{Results}

\subsection{Methodological Rationale}

Path analysis is appropriate for testing model fitness and in other conditions where common sense or existent findings point to probable relationships (Cook \& Campbell, 1979). It is a comprehensive methodology, which is appropriate for investigating achievements, self-concepts, and self-efficacy among other phenomenon (Suhr, 2008). The model used in this study focuses on examining direct effects between three exogenous variable (learning preference, intrinsic motivation, and extrinsic motivation) and three endogenous variables (self-efficacy, coding achievement, and computational thinking skills). Exogenous variables are not influenced by other variables in the model, so learning preference, intrinsic motivation, and extrinsic motivation are variables without observed influences. Lastly, the sample size $(n=122)$ satisfies the criteria for the lower bounds of sample size for any type of Structural Equation Modeling (SEM). According to Anderson and Gerbing (1988), the threshold is approximately 87 participants for models that are comprised of three to four indicators.

\subsection{Path Analysis}

To check that there are no questionable relationships between the variables presented in the model, a Pearson Correlation analysis was conducted. Results show that all variables were significantly correlated to self-efficacy (Table 1). No link was dropped for the hypothesis model as discussed in the next section.

A path analysis was conducted to investigate the relationships depicted in the hypothesized model. At first, the model showed poor fit $\chi^{2}(\mathrm{df}=8, \mathrm{~N}=122)=17.47, \mathrm{p}<.05$; RMSEA $=0.099$; AGFI $=.882$; NFI $=.852$. The model also showed that the paths from learning preference to self-efficacy $(\beta=.041, \mathrm{p}=.087)$ and from extrinsic motivation to coding achievement $(\beta=.039, \mathrm{p}=.140)$ were insignificant. Consequently, these two paths were dropped from the model and the model was re-analyzed.

The result of the second path analysis indicated that the model was a fit to the data, $\chi 2(\mathrm{df}=5, \mathrm{~N}=122)=8.08, \mathrm{p}=$ .152 . The fit indexes were excellent (RMSEA $=0.71$; AGFI $=.918$; NFI $=.922$ ); 90\% Confidence Interval (CI) for RMSEA: $(0.00 ; 0.158)$, pClose $=.288$. All paths in this revised model were significant (see Figure 3 ).

\subsection{Multiple Regression Analyses}

In addition to path analysis, a series of multiple regression analyses were conducted to explore the relationships depicted in the hypothesized and revised models. It was found that intrinsic motivation $(B=.328, p<0.01)$, and extrinsic motivation $(\mathrm{B}=.183, \mathrm{p}<0.01$ ) were significant predictors of self-efficacy. Self-efficacy was a significant predictor of coding achievement $(\mathrm{B}=.174, \mathrm{p}<0.01)$ and coding achievement $(\mathrm{B}=.444, \mathrm{p}<0.01)$ was a significant predictor of computational thinking skills (Table 4).

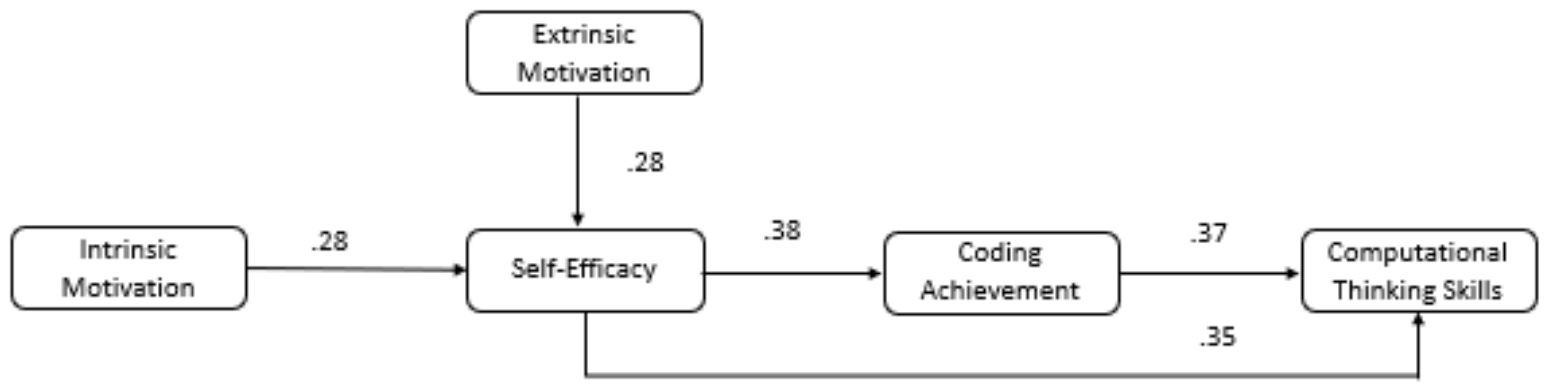

Figure 3. The final path model 
Table 2

Correlation matrix

\begin{tabular}{lcccccc}
\hline & 1 & 2 & 3 & 4 & 5 & 6 \\
\hline 1. Learning preference & - & .090 & .147 & $.201^{*}$ & $.195^{*}$ & $.317^{* *}$ \\
2. Intrinsic Motivation & .090 & - & .159 & $.319^{* *}$ & $.253^{* *}$ & $.205^{*}$ \\
3. Extrinsic Motivation & .147 & .159 & - & $.321^{* *}$ & $.237^{* *}$ & .158 \\
4. Self-Efficacy & $.201^{*}$ & $.319^{* *}$ & $.321^{* *}$ & - & $.380^{* *}$ & $.489^{* *}$ \\
& & & & & & \\
5. Coding Achievement & $.195^{*}$ & $.253^{* *}$ & $.237^{* *}$ & $.380^{* *}$ & - & $.503^{* *}$ \\
& & & & & & \\
6. Computational Thinking & $.317^{* *}$ & $.205^{*}$ & .158 & $.489^{* *}$ & $.503^{* *}$ & - \\
\hline
\end{tabular}

Note: ${ }^{*} \mathrm{p}<.05$, two-tailed. ${ }^{* *} \mathrm{p}<.01$, two-tailed. $\mathrm{N}=122$ 
Table 3

Goodness-of-fit indices for the total sample $(N=122)$

Fit Statistics

\begin{tabular}{ccccccc}
\hline$\chi^{2}$ & df & RMSEA & GFI & AGFI & TLI & CFI \\
8.083 & 5 & 0.71 & .973 & .918 & .934 & .967 \\
\hline
\end{tabular}

Path

Path Estimates

\begin{tabular}{ll}
\hline Intrinsic Motivation $\rightarrow$ Self-Efficacy & $.328^{* *}$ \\
Extrinsic Motivation $\rightarrow$ Self-Efficacy & $.183^{* *}$ \\
Self-Efficacy $\rightarrow$ Coding Achievement & $.174^{* *}$ \\
Self-Efficacy $\rightarrow$ Computational Thinking & $.192^{* *}$ \\
Coding Achievement $\rightarrow$ Computational Thinking & $.441^{* *}$ \\
\hline Note: ${ }^{*} \mathrm{p}<.05 ;{ }^{* *} \mathrm{p}<0.01$ &
\end{tabular}


This is an author-produced, peer-reviewed version of this article. The final, definitive version of this document can be found online at Information Discovery and Delivery, published by Emerald Group Publishing, Ltd. Copyright restrictions may apply. doi: 10.1108/IDD-092019-0065

Table 4

Multiple regression analysis

\begin{tabular}{llcccc}
\hline Predictor(s) & $\begin{array}{l}\text { Dependent } \\
\text { Variable }\end{array}$ & B & SE B & $\beta$ & t \\
\hline 1. Intrinsic Motivation & Self-Efficacy & .328 & .100 & $.275^{* *}$ & 3.264 \\
2. Extrinsic Motivation & & .183 & .056 & $.278^{* *}$ & 3.298 \\
\hline 1. Self-Efficacy & $\begin{array}{c}\text { Coding } \\
\text { Achievement }\end{array}$ & .174 & .039 & $.380^{* *}$ & 4.505 \\
\hline 1. Self-Efficacy & $\begin{array}{c}\text { Computational } \\
\text { Thinking } \\
\text { 2. Coding Achievement }\end{array}$ & .192 & .044 & $.349^{* *}$ & 4.383 \\
& Skills & .444 & .095 & $.370^{* *}$ & 4.655 \\
\hline${ }^{* *} p<0.01, \mathrm{~N}=122$ & & & & &
\end{tabular}

\subsection{Hypothesis Testing}

First, to address the research question stated earlier which inquired about the factors that influence both coding and computational thinking skills of second grade students in robotics activities, final analysis has shown that self-efficacy was significantly influenced by intrinsic and extrinsic motivation, with both factors having the same amount of influence. Coding achievement was only directly influenced by self-efficacy, while intrinsic and extrinsic motivation had no direct influence on coding achievement.

As shown in Table 1 and 3, the seven hypotheses presented in this study were all supported. The model shows that the relationship between self-efficacy and coding achievement was the strongest in the model. However, in the final path model, learning preference did not predict self-efficacy. Intrinsic and extrinsic motivation were positively correlated with self-efficacy. As such, H2 and H3 were supported. Self-efficacy was also positively correlated with computational thinking skills, which supported H6. In the final path model, intrinsic and extrinsic motivation predicted self-efficacy. Coding achievement is positively correlated with extrinsic motivation, self-efficacy, and computational thinking skills. Thus, H4, H5, and H7 were supported. Self-efficacy was the most important factor predicting coding achievement and computational thinking skills.

\section{Discussions}

Several studies have revealed a positive relationship between intrinsic motivation and self-efficacy (e.g., Hong et al., 2017; Kılıçoğlu, 2018). For instance, Hong et al. (2017) found that the intrinsic motivation of Chinese learning could predict online learning self-efficacy. Kılıçoğlu (2018) found that intrinsic motivation combined with extrinsic motivation and academic achievement could predict students' social studies self-efficacy and could explain $64 \%$ of the variance in self-efficacy. Therefore, this study hypothesized that students' intrinsic motivation was positively related to self-efficacy. The correlation analysis showed that intrinsic motivation is positively related to self-efficacy $(\mathrm{p}<.01)$, which confirmed $\mathrm{H} 2$ in this study. The multiple regression analysis results further indicated that intrinsic motivation was a significant predictor of self-efficacy $(\mathrm{B}=.328, \mathrm{p}<0.01)$. Even though several previous studies have investigated the relationship between intrinsic motivation and self-efficacy across different fields, for example, in Chinese language learning (Hong et al., 2017) and social studies (Kılıçoğlu, 2017), few studies were conducted in the field of robotics (computational thinking). This study addressed this research gap and showed a positive relationship between intrinsic motivation and self-efficacy in robotics. Moreover, as suggested by the regression analysis result, intrinsic motivation was a significant predictor of self-efficacy, which could have implications for the instruction of robotics in elementary school settings. 
This is an author-produced, peer-reviewed version of this article. The final, definitive version of this document can be found online at Information Discovery and Delivery, published by Emerald Group Publishing, Ltd. Copyright restrictions may apply. doi: 10.1108/IDD-092019-0065

Various studies have been conducted to investigate the relationship between extrinsic motivation and self-efficacy (e.g., Kılıçoğlu, 2018; Liao et al., 2014; McGeown et al., 2014). For instance, Kılıçoğlu (2018) suggested that extrinsic motivation combined with intrinsic motivation and academic achievement could explain $64 \%$ of the variance in selfefficacy. Liao et al. (2014) study revealed a strong correlation between self-efficacy and extrinsic motivation. By contrast, McGeown et al.’s (2014) study suggested a reverse relationship between extrinsic motivation and selfefficacy, indicating that self-efficacy could explain significant variances in extrinsic motivation. The above reviewed studies confirmed an existing relationship between self-efficacy and extrinsic motivation no matter which one served as the predictive variable. This study, therefore, hypothesized that students' extrinsic motivation is positively related to self-efficacy, and the correlation analysis confirmed this hypothesis $(\mathrm{p}<.01)$. The multiple regression analysis revealed that extrinsic motivation was a significant predictor of self-efficacy $(B=.183, p<0.01)$. The correlation analysis results in this study corroborated the previous studies and addressed the research gap by showing that extrinsic motivation could significantly predict students' self-efficacy in the robotics teaching in elementary schools.

While few studies have directly investigated the relationship between self-efficacy and coding achievement and computational thinking skills, there were studies revealing a positive relationship between self-efficacy and academic performance (e.g., Richardson et al., 2012; Robbins et al., 2004). In this study, both students' coding achievement and computational thinking skills could be included under the realm of academic performance. Therefore, it was hypothesized that student's self-efficacy is positively related to coding achievement, and student's self-efficacy is positively related to computational thinking skills. Both hypotheses were supported by the correlation analysis results, with a correlation coefficient between self-efficacy and coding achievement as $.380(\mathrm{p}<.01)$, and a correlation coefficient between self-efficacy and computational thinking skills as $.489(\mathrm{p}<.01)$. The multiple regression analysis results in this study suggested that self-efficacy could significantly predict students' coding achievement $(B=.174, p$ $<0.01)$ and computational thinking skills $(\mathrm{B}=.192, \mathrm{p}<0.01)$. As mentioned earlier, there was a paucity of studies investigating the relationship between self-efficacy and coding achievement and computational thinking skills respectively. This study, therefore, addressed the research gap and supplements the existing literature. Moreover, the multiple regression results suggested that self-efficacy was a significant predictor in predicting students' coding achievement and computational thinking skills, which could have important implications for the robotics instruction in elementary schools.

In coding activities, the students would practice the key components included in computational thinking, which implies that students engaged in coding activities will normally practice computational thinking skills. Therefore, even though few studies have been conducted to investigate the relationship between coding achievement and computational thinking skills, this study hypothesized that student's coding achievement is positively related to computational thinking skills, which was evidenced by the correlation analysis results in this study $(\mathrm{p}<.01)$. The multiple regression analysis results showed that students' coding achievement was a significant predictor of their computational thinking skills $(\mathrm{B}=.444, \mathrm{p}<0.01)$. The examination of the positive relationship between coding achievement and computational thinking skills was scarce in existing literature, therefore, the result filled the research gap.

The correlation analysis indicated a positive correlation between learning preference and self-efficacy $(\mathrm{p}<.05)$, which supported the $\mathrm{H} 1$ in this study. The path analysis showed that the path between them was not significant $(\mathrm{B}=.041$, $\mathrm{p}=$.087). Therefore, the path between learning preference and self-efficacy was dropped from the final model, and was not analyzed in the multiple regression procedure. Moreover, the correlation analysis results showed that extrinsic motivation was positively related to coding achievement with a correlation coefficient as .237 ( $p<.01)$, however, since path analysis suggested that the path between extrinsic motivation and coding achievement was not significant $(\mathrm{B}=.039, \mathrm{p}=.140)$, the path was therefore dropped from the final model and was not analyzed in the multiple regression.

The correlation analysis results confirmed all the seven hypotheses in this study, and the same results could be found in previous studies (e.g., Kılıçoğlu, 2018; Liao et al., 2014; McGeown et al., 2014). Moreover, this study addressed some research gaps by investigating the relationships between intrinsic motivation and self-efficacy, self-efficacy and coding achievement, and self-efficacy and computational thinking. 
This is an author-produced, peer-reviewed version of this article. The final, definitive version of this document can be found online at Information Discovery and Delivery, published by Emerald Group Publishing, Ltd. Copyright restrictions may apply. doi: 10.1108/IDD-092019-0065

\section{Conclusions and Implications for Further Studies}

As indicated by the correlation analysis results, all seven hypotheses proposed in this study were well supported. A research model was built based on the analysis results of path analysis and multiple regression analysis. This hypothesized model showed that learning preference, intrinsic motivation and self-efficacy were the main predictors of coding achievement and computational thinking skills, while no direct relationship was found between learning preference, intrinsic and extrinsic motivation. The final path analysis revealed that intrinsic and extrinsic motivation predicts self-efficacy, self-efficacy predicts coding achievement, and coding achievement predicts computational thinking skills. Another important finding was the strong impact of self-efficacy on coding achievement and on computational thinking skills as well.

The research findings have several important implications for both the research and practice in robotics instruction in elementary schools. First, the examination of relationships as described above in the discussion section addressed research gaps existing in the literature on the personal traits related to second grader's computational thinking skills. Specifically, few studies have investigated the various relationships in the context of robotics instruction in elementary schools as in this study. For instance, the relationship between self-efficacy and coding achievement, the relationship between motivation and self-efficacy, and the relationship between self-efficacy and computational thinking skills, etc. Given the increasing popularity of robotics education in elementary schools, the re-examination and identification of the pivotal role of self-efficacy in predicting second graders' learning of coding and computational thinking skills have important implications for the implementation of robotics education. Knowing the important role of self-efficacy, instructors may measure students' self-efficacy levels prior to the formal implementation of robotics curricula. And special attention may, therefore, be allocated to those students with relatively low self-efficacy by designing specific activities that could boost their self-efficacy. In this way, it is more likely that students' coding achievement and computational thinking skills could be improved. Therefore, when teaching robotics in elementary education to improve students' computational thinking skills, teachers could consider boosting students' self-efficacy as a starting point. Second, this study not only examined these relationships, but also it proposed, tested, and built a research model containing a wide range of personal traits based on path analysis and multiple regression analysis, which, to the best of the researchers' knowledge, has not been investigated in the current literature. Hence, this gap was filled by this study by building a research model which could be an important reference for future studies on robotics education in elementary schools. The research model contains several prominent variables in influencing learning processes as identified in current literature, for instance, intrinsic motivation (Grant, 2008; Ryan \& Deci, 2000), extrinsic motivation (Ryan \& Deci, 2000), and self-efficacy (Gappi, 2013; Kuo et al., 2015), and presents a comprehensive picture of what individual traits could predict the learning of coding and computational thinking skills in robotics education in elementary settings. Future studies could use this research model as a starting point and extend it by adding more personal traits (e.g., gender) to explore the factors impacting the learning of coding and computational thinking skills. Third, as reflected in the final research model, self-efficacy played an important role in impacting second grader's coding achievement and computational thinking skills. Therefore, in the instruction of robotics in elementary school settings, attention should be focused not only on the development of students coding skills, but an adequate amount of attention should also be paid to students' self-efficacy (i.e., in grouping students).

Even though it was suggested in this study that learning preference has a positive relationship with self-efficacy, it was dropped from the final model due to its insignificant result in path analysis. Given its evident importance, more studies should be conducted to further investigate its role in impacting students' learning of coding and computational thinking skills in the context of robotics education.

\section{Acknowledgement}

We wish to thank the National Science Foundation (NSF) for the support of this study under Grant Number 1640228. Any opinions, findings, and conclusions or recommendations expressed in this material are those of the authors and do not necessarily reflect the views of the NSF. 
This is an author-produced, peer-reviewed version of this article. The final, definitive version of this document can be found online at Information Discovery and Delivery, published by Emerald Group Publishing, Ltd. Copyright restrictions may apply. doi: 10.1108/IDD-092019-0065

\section{References}

Aesaert, K., \& Van Braak, J. (2014). Exploring factors related to primary school pupils’ ICT self-efficacy: A multilevel approach. Computers in Human Behavior, 41, 327-341. https://doi.org/10.1016/j.chb.2014.10.006

Alivernini, F., \& Lucidi, F. (2011). Relationship between social context, self-efficacy, motivation, academic achievement, and intention to drop out of high school: A longitudinal study. The Journal of Educational Research, 104, 241-252. https://doi.org/10.1080/00220671003728062

Atmatzidou, S., \& Demetriadis, S. (2016). Advancing students' computational thinking skills through educational robotics: A study on age and gender relevant differences. Robotics and Autonomous Systems, 75, 661-670. https://doi.org/10.1016/j.robot.2015.10.008

Baker, L., \& Wigfield, A. (2011). Dimensions of children's motivation for reading and their relations to reading activity and reading achievement. Reading Research Quarterly, 34(4), 452-477. https://doi.org/10.1598/RRQ.34.4.4

Bandura, A. (1977). Self-efficacy: Toward a unifying theory of behavioral change. Psychological Review, 84(2), 191-215.

Bandura, A. (1986). Social foundations of thought and action: A social cognitive theory. Englewood Cliffs, NJ: Prentice Hall.

Barker, B. S., \& Ansorge, J. (2007). Robotics as means to increase achievement scores in an informal learning environment. Journal of Research on Technology in Education, 39(3), 229-243. https://doi.org/10.1080/15391523.2007.10782481

Blanchard, S., Freiman, V., \& Lirrete-Pitre, N. (2010). Strategies used by elementary school children solving robotics-based complex tasks: innovative potential of technology. Procedia Social and Behavioral Sciences, 2, 2851-2857. https://doi.org/10.1016/j.sbspro.2010.03.427

Chang, C. W., Lee, J. H., Chao, P. Y., Wang, C. Y., \& Chen, G. D. (2010). Exploring the possibility of using humanoid robots as instructional tools for teaching a second language in primary school. Journal of Education Technology \& Society, 13(2), 13-24. https://doi.org/https://www.jets.net/ETS/journals/13_2/2.pdf

Chen, G., Shen, J., Barth-Cohen, L., Jiang, S., Huang, X., \& Eltoukhy, M. (2017). Assessing elementary students' computational thinking in everyday reasoning and robotics programming. Computers \& Education, 109, 162-175. https://doi.org/10.1016/j.compedu.2017.03.001

Cook, T. D., \& Campbell, D. T. (1979). Quasi-experimentation: Design \& analysis issues for field settings. Boston: Houghton Mifflin.

de Brabander, C. J., \& Martens, R. L. (2014). Towards a unified theory of task-specific motivation. Educational Research Review, 11, 27-44. https://doi.org/10.1016/j.edurev.2013.11.001

Deci, E. L., \& Ryan, R. M. (1985). Intrinsic motivation and self-determination in human behavior. New York, NY: Plenum.

Duff, A. (2004) A note on the problem solving style questionnaire: An alternative to Kolb's learning style inventory?, Educational Psychology, 24 (5), 699-709, https://doi.org/10.1080/0144341042000262999

Elias, S. M., \& MacDonald, S. (2007). Using past performance, proxy efficacy, and academic self-efficacy to predict college performance. Journal of Applied Social Psychology, 37, 2518-2531. https://doi.org/10.1111/j.15591816.2007.00268.x

Gappi, L. L. (2013). Relationships between learning style preferences and academic performance of students. International Journal of Educational Research and Technology, 4(2), 70-76. Retrieved from www.soeagra.com/ijert/ijert.htm

Gomoll, A., Hmelo-Silver, C. E., Šabanović, S., \& Francisco, M. (2016). Dragons, ladybugs, and softballs: Girls' STEM engagement with human-centered robotics. Journal of Science Education and Technology, 25(6), 899-914. https://doi.org/10.1007/s10956-016-9647-z

Grant, A. M. (2008). Does intrinsic motivation fuel the prosocial fire? Motivational synergy in predicting persistence, performance, and productivity. Journal of Applied Psychology, 93(1), 48-58. https://doi.org/10.1037/0021-9010.93.1.48

Hanus, M. D., \& Fox, J. (2015). Assessing the effects of gamification in the classroom: A longitudinal study on intrinsic motivation, social comparison, satisfaction, effort, and academic performance. Computers \& Education, 80 (c). 151-161._https://doi.org/10.1016/j.compedu.2014.08.019

Hong, J. C., Yu, K. C., \& Chen, M. Y. (2011). Collaborative learning in technological project design. International Journal Technology \& Design Education, 21, 335-347. https://doi.org/10.1007/s10798-010-9123-7 
This is an author-produced, peer-reviewed version of this article. The final, definitive version of this document can be found online at Information Discovery and Delivery, published by Emerald Group Publishing, Ltd. Copyright restrictions may apply. doi: 10.1108/IDD-092019-0065

Hong, J. C., Hwang, M. Y., Tai, K. H., \& Lin, P. H. (2017). Intrinsic motivation of Chinese learning in predicting online learning self-efficacy and flow experience relevant to students' learning progress. Computer Assisted Language Learning, 30(6), 552-574. https://doi.org/10.1080/09588221.2017.1329215

Honicke, T., \& Broadbent, J. (2016). The influence of academic self-efficacy on academic performance: A systematic review. Educational Research Review, 17, 63-84. https://doi.org/10.1016/j.edurev.2015.11.002

Huang, H.-M., \& Liaw, S.-S. (2007). Exploring learners' self-efficacy, autonomy, and motivation toward e-learning. Perceptual and Motor Skills, 105(6), 581-586. https://doi.org/10.2466/pms.105.6.581-586

Ioannou, A., \& Makridou, E. (2018). Exploring the potentials of educational robotics in the development of computational thinking: A summary of current research and practical proposal for future work. Education and Information Technologies, 23, 2531-2544. https://doi.org/10.1007/s10639-018-9729-z

Joët, G., Usher, E. L., \& Bressoux, P. (2011). Sources of self-efficacy: An investigation of elementary school students in France. Journal of Educational Psychology, 103, 649-663. https://doi.org/10.1037/a0024048

Kilıçoğlu, G. (2018). Study on the relationship between social studies course self-efficacy and motivation levels of secondary school students. Universal Journal of Educational Research, 6(8), 1743-1748. https://doi.org/10.13189/ujer.2018.060816

Kuo, Y.-C., Chu, H.-C., \& Huang, C.-H. (2015). A learning style-based grouping collaborative learning approach to improve EFL students' performance in English courses. Journal of Educational Technology \& Society, 18(2), 284-298. Retrieved from https://www.j-ets.net/ETS/index.html

Leonard, J., Buss, A., Gamboa, R., Mitchell, M., Fashola, O. S., Hubert, T., \& Almughyirah, S. (2016). Using robotics and game design to enhance children's self-efficacy, STEM attitudes, and computational thinking skills. Journal of Science Education and Technology, 25, 860-876. https://doi.org/10.1007/s10956-0169628-2

Liao, H. A., Edlin, M., \& Ferdenzi, A. C. (2014). Persistence at an urban community college: The implications of self-efficacy and motivation. Community College Journal of Research and Practice, 38, 595-611. https://doi.org/10.1080/10668926.2012.676499

Master, A., Cheryan, S., Moscatelli, A., \& Meltzoff, A. N. (2017). Programming experience promotes higher STEM motivation among first-grade girls. Journal of Experimental Child Psychology, 160, 92-106. https://doi.org/10.1016/j.jecp.2017.03.013

McAuley, E., Duncan, T., \& Tammen, V. V. (1987). Psychometric properties of the Intrinsic Motivation Inventory in a competitive sport setting: A confirmatory factor analysis. Research Quarterly for Exercise and Sport, 60, 48-58.

McGeown, S. P., Putwain, D., Geijer Simpson, E., Boffey, E., Markham, J., \& Vince, A. (2014). Predictors of adolescents' academic motivation: Personality, self-efficacy and adolescents' characteristics. Learning and Individual Differences, 32, 278-286. https://doi.org/10.1016/j.lindif.2014.03.022

Oxford, R., \& Shearin, J. (1994). Language learning motivation: Expanding the theoretical framework. The Modern Language Journal, 78(1), 12-28. https://doi.org/10.2307/329249

Ozgen, K. (2013). An analysis of high school students' mathematical literacy self-efficacy beliefs in relation to their learning styles. Asia-Pacific Education Researcher, 22(1), 91-100. https://doi.org/10.1007/s40299-0120030-4

Richardson, M., Bond, R., \& Abraham, C. (2012). Psychological correlates of university students’ academic performance: a systematic review and meta analysis. Psychological Bulletin, 138, 353-387. https://doi.org/10.1037/a0026838

Robbins, S. B., Lauver, K., Le, H., David, D., \& Langley, R. (2004). Do psychosocial and study skill factors predict college outcomes? A meta-analysis. Psychological Bulletin, 130, 261-288. https://doi.org/10.1037/00332909.130.2.261

Roman-Gonzalez, M. (2015). Computational thinking test: Design guidelines and content validation. Proceedings of EDULEARN15 Conference (pp. 2436-2444). Barcelona, Spain.

Ryan, R. M., \& Deci, E. L. (2000). Self-determination theory and the facilitation of intrinsic motivation, social development and well-being. American Psychologist, 55(1), 68-78. https://doi.org/10.1037/0003066X.55.1.68

Ryan, R. M. (1982). Control and information in the intrapersonal sphere: An extension of cognitive evaluation theory. Journal of Personality and Social Psychology, 43, 450-461. https://doi.org/10.1037/00223514.43.3.450

Ryan, R. M., Mims, V., \& Koestner, R. (1983). Relation of reward contingency and interpersonal context to intrinsic motivation: A review and test using cognitive evaluation theory. Journal of Personality and Social Psychology, 45, 736-750. https://doi.org/10.1037/0022-3514.45.4.736 
This is an author-produced, peer-reviewed version of this article. The final, definitive version of this document can be found online at Information Discovery and Delivery, published by Emerald Group Publishing, Ltd. Copyright restrictions may apply. doi: 10.1108/IDD-092019-0065

Ryan, R. M., Koestner, R., \& Deci, E. L. (1991). Varied forms of persistence: When free-choice behavior is not intrinsically motivated. Motivation and Emotion, 15, 185-205.

Sengupta, P., Kinnebrew, J. S., Basu, S., Biswas, G., \& Clark, D. (2013). Integrating computational thinking with K12 science education using agent-based computation: A theoretical framework. Education and Information Technologies, 18, 351-380. https://doi.org/10.1007/s10639-012-9240-x

Shiue, Y.-M. (2005). The effects of cognitive learning style and prior computer experience on Taiwanese college students' computer self-efficacy in computer literacy courses. Journal of Educational Technology Systems, 31(4), 393-409. https://doi.org/10.2190/8qcn-63qg-dppq-517n

Sullivan, F. R. (2008). Robotics and science literacy: Thinking skills, science process skills and systems understanding. Journal of Research in Science Teaching, 45(3), 373-394. https://doi.org/10.1002/tea.20238

Suhr, D. (2008). Step your way through path analysis. In Western Users of SAS Software Conference Proceedings. Retrieved from http://lexjansen.com/wuss/2008/pos/pos04.pdf

Wing, J. M. (2006). Computational thinking. Communications of the ACM, 49(3), 33-35. https://doi.org/10.1145/1118178.1118215

Xia, L., \& Zhong, B. (2018). A systematic review on teaching and learning robotics content knowledge in K-12. Computers \& Education, 127, 267-282. https://doi.org/10.1016/j.compedu.2018.09.007

Yadav, A., Hong, H., \& Stephenson, C. (2016). Computational thinking for all: Pedagogical approaches to embedding 21st century problem solving in K-12 classrooms. TechTrends, 60, 565-568. https://doi.org/10.1007/s11528-016-0087-7

Yang, D., Chittoori, B., Fan, Y., Baek, Y., Ching, Y.-H., Wang, S., \& Swanson, S. (2019). Assessing computational thinking in a project-based STEM+CT learning environment. In 2019 AERA Annual Meeting. Toronto.

Zhong, B., Wang, Q., Chen, J., \& Li, Y. (2016). An exploration of three-dimensional integrated assessment for computational thinking. Journal of Educational Computing Research, 53(4), 562-590. https://doi.org/10.1177/0735633115608444 